\title{
Application and Research of Recyclable Cables in Foundation Pit Support
}

\section{Engineering}

\author{
Zheng Suping \\ (School of Engineering, Jiangxia University, Fuzhou Fujian 350108, China)
}

\begin{abstract}
Anchoring cables are widely used in the construction of foundation pit as a temporary support structure. After the construction is completed, the anchor cables left in the ground will not only cause environmental pollution but also cause a great waste of resources. The emergence of recyclable cable technology, to avoid such problems, to achieve the secondary use of the anchor cable, excavation in the excavation project is more and more widely used. Combined with the design and construction of recoverable anchor cable in engineering practice, the application effect of recoverable anchor cable in foundation pit support is analyzed, and the conclusion that the support effect of recoverable anchor cable is stable and safe can be obtained Recyclable anchor cable in the future support projects to provide a reference.
\end{abstract}

Keywords: foundation pit support; prestressed anchor cable; recyclable anchor cable; control measures

\section{Introduction}

At present, in the modern building foundation pit support technology, the anchor cable reinforcement technology is a widely used method. Foundation pit support structure as a temporary structure, after the completion of the basement roof pouring, it lost its effectiveness. Traditional anchor cables, together with the remaining structures, will be buried underground for a long time, causing serious pollution to the underground environment and severely affecting the construction of adjacent plots and the long-term urban planning and sustainable development. Another In terms of steel are non-renewable resources, buried in the ground anchor also caused a great waste of resources. Recyclable Anchors after the function is completed, the cables are recovered from the borehole. This can greatly reduce the pollution and impact. Therefore, the country is vigorously promoting the use of recyclable cables in the excavation support.

\section{Recyclable type of anchor}

The main part of recyclable cable retrieval is strand, while the remaining cement mortar, bellows and other attachments remain in the rock mass. Recyclable cables have been researched all over the world and recyclable cables have been developed in various ways. Recyclable cable by the way of recovery to distinguish can be divided into mechanical recovery, chemical recovery and physical recovery of three recovery methods [1].

Mechanical recovery usually involves attaching the strand to the anchorage end via a connector, disengaging it from the anchorage end by tensioning the anchor cable or rotating the anchor cable in the opposite direction during recovery; the chemical recovery is usually done on the strand connector Strong acids or strong alkaline devices that separate the strand from the anchorage end when the device is started up during recovery. Physical Methods Recycling is usually performed by attaching heating coils or small blasting devices to the strand connections, starting the device on recovery, then recycle the strand.

In recent years, many scholars at home and abroad have carried out a large number of experiments and studies on recyclable cables, and have developed various forms of recharging and anchoring cables. Some of them have been used in engineering practice to create economic benefits. Based on the engineering example, this paper introduces a new type of reusable anchor cable - prestressing tendon detachable anchor head, the anchor cable is a mechanical 
method of recovery, the following we project examples to discuss the kind Recyclable anchor some construction points and so on.

\section{Project Overview}

\subsection{Site Overview}

Site is located in Cangshan District, Fuzhou City, and the proposed venue west of Fuzhou near a sports center. The total area of the project is $37137.56 \mathrm{~m}^{2}$, and the first total building area is $98500 \mathrm{~m}^{2}$. The proposed building is composed of a 5F-10F single building complex, the structure of the complex body, from the 10F hospital building, 5F outpatient health building, $5 \sim 6 \mathrm{~F}$ hospital medical technology complex and 2 storey basement, etc. composition. The high-rise building adopts frame shear structure, multi storey building adopts frame structure, and the basement adopts frame structure.

The project consists of two basements. The average elevation of the floor surface is $-9.90 \mathrm{~m}$. The thickness of the bottom plate is $600 \mathrm{~mm}$. The bottom of the bottom plate is provided with a $1500 \mathrm{~mm}$ thick cushion. The depth of the bottom of the foundation pit excavation to the bottom cushion is $10.65 \mathrm{~m}$. Foundation pit support circumference of about 510m, a security level. The foundation pit support plan as shown in Figure 1.

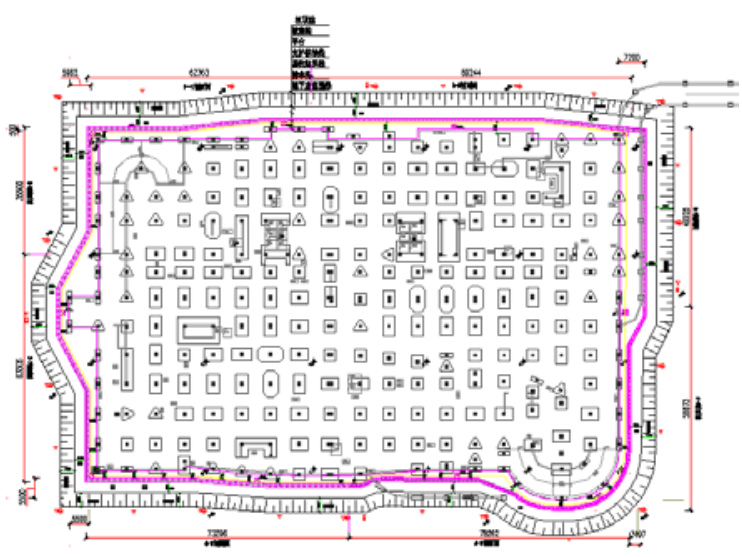

Fig.1 Layout of excavation

\subsection{Engineering Geological Conditions}

The proposed site cover mainly Quaternary flood sediment and alluvial sedimentary facies deposition, the basement is intrusive rock. Quaternary Artificial Filling Layer (Qml) on the surface and miscellaneous fillings of lithology (1) Upper Quaternary Holocene alluvial strata (Q4al-m) on the south side with lithology of silty clay and silt; Middle (Q3al-pl) of the Quaternary. The lithology is composed of gravelly silty clay and silt soil. The lower part of the Quaternary Pleistocene Qpel-pl is lithologic the residual gravelly clayey soil is exposed to the ground surface at the northeast corner of the site. The basement is granite $(\gamma 53)$ and its weathering layer intrusive in the late Yanshanian period, and the diabase dykes are partially penetrated. The physical and mechanical parameters of each layer of the proposed site are shown in Table 1. 
Table 1 Physical-mechanical parameters of soil layers

\begin{tabular}{ccccc}
\hline $\begin{array}{c}\text { Serial } \\
\text { number }\end{array}$ & Soil name & $\begin{array}{c}\text { Natural bulk density } \gamma \\
(\mathrm{KN} / \mathrm{m} 3)\end{array}$ & $\begin{array}{c}\text { Cohesion C } \\
(\mathrm{Kpa})\end{array}$ & $\begin{array}{c}\text { Internal friction } \\
\text { angle } \varphi\left({ }^{\circ}\right)\end{array}$ \\
\hline (1) & Miscellaneous fill & 17.5 & 8 & 20 \\
$(2)$ & Silty clay & 17.9 & 20.1 & 7.2 \\
$(3)$ & silt & 16.2 & 13.6 & 1.4 \\
$(4)$ & Boulder silty clay & 18.8 & 30.4 & 21.8 \\
$(5)$ & Muddy soil & 16.2 & 22.1 & 3.4 \\
$(6)$ & Boulder silty clay & 18.7 & 26.3 & 20.5 \\
$(7)$ & Residual sandy clay & 17.9 & 20.1 & 25.2 \\
\hline
\end{tabular}

\subsection{Hydrogeological conditions}

The groundwater types of the proposed site mainly include: (1) pore diving, which occurs in the upper weak aquifer, and the main rock and soil are miscellaneous fill (1), gravelly silty clay (4) and gravelly silty clay (6), etc. Generally poor water quality and uneven distribution, the main sources of supply for the precipitation and surface water around the site; (2) bedrock weathering pore fissure water, occurring in the weathered rock and residual gravel cohesive soil (7) less water-rich , Silt (3) and muddy soil (5) as the relative aquifuge, was discontinuous distribution, the layer and the upper weak aquifer hydraulic connection, the overall lack of water, the main supply source of the upper aquifer and groundwater lateral replenishment, to the lower excretion. During the survey, groundwater mixed with water depth $0.40 \sim 5.10 \mathrm{~mm}$, elevation $6.99 \sim 7.35 \mathrm{~m}$. The pit adopts $\varnothing 700$ high-pressure rotary jet grouting water-proof curtain to prevent water leakage and pit to collect water.

\section{Foundation pit support design}

\subsection{Envelope design}

The foundation pit design has two basements, excavation depth is relatively large, the basic excavation depth of about $11 \mathrm{~m}$, according to the specification, the safety level of the foundation pit belongs to one; in the excavation of the main excavation area of the main soil is filled Soil, silty clay, silt, gravelly silty clay, muddy soil, physical and mechanical properties of the soil generally poor, less water permeability, muddy soil layer thickness is relatively large; Pit shape is generally more regular, Nearly a rectangle; the surrounding environment is poor, the west side of the foundation pit adjacent to the Sports Center has been built, the southern side of the city roads close to the basic no grading conditions.

According to the above characteristics, the foundation pit supports the bored pile and the anchor-pull type envelopment structure: the bored pile is punched and filled pile, the section of the bored pile is $\varphi 800$ and the spacing is about 1200-1600; the anchor cable is recyclable Anchor; 4-4,5-5 section retaining pile between the use of $\varphi 700$ high-pressure rotary jet grouting stop water retaining, the rest of the section between the injection of reinforced concrete piles, excavation surface and basement shear wall between Set aside more than 30mm distance, convenient enough space to recover the anchor cable. The typical section of foundation pit support is shown in Figure 2 below. 


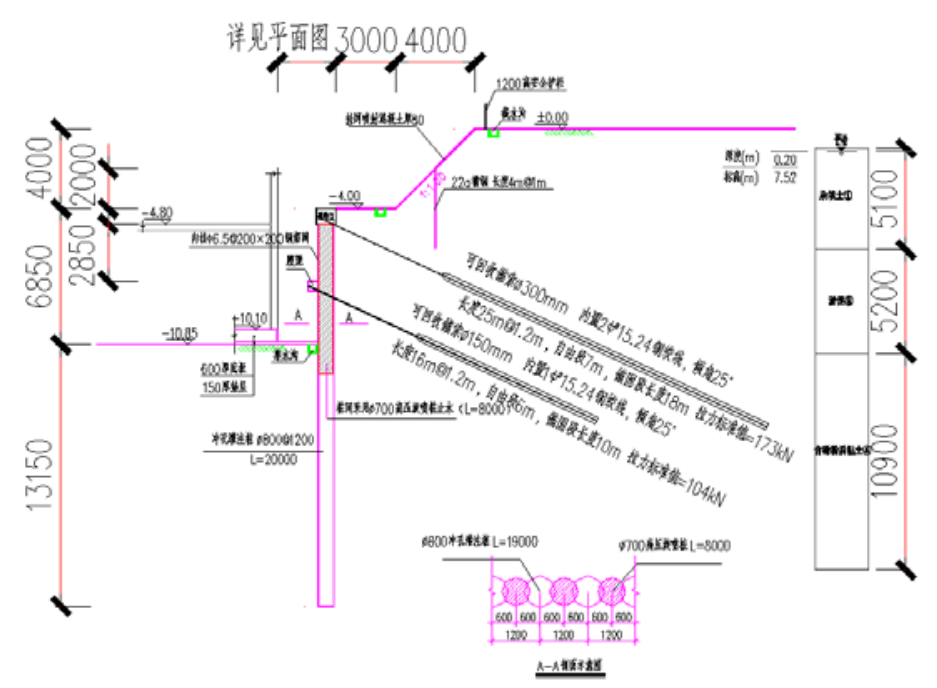

Fig.2 Foundation supporting section

\subsection{Foundation pit precipitation program design}

The excavation within the scope of this foundation, the groundwater level is shallow, so in the construction process should be used precipitation measures. Within the excavation area of the foundation pit, 24 precipitation wells and 8 recharge wells were arranged according to the actual conditions of the site. The depth of the dewatering wells was about 14 meters (from the existing ground). Dewatering wells into the hole according to formation conditions, the use of auger hole, with a hole diameter of $400 \mathrm{~mm}$; drilling to reach the design depth, should drill more 0.3-0.5 meters, with a large pump flushing slurry to reduce precipitation, and immediately under the tube , The tube well using welded pipe, diameter $219 \mathrm{~mm}$, wall thickness of not less than 1.8 , the porosity of the filter tube should not be less than $23 \%$, the choice of gravel net filter tube, pipe connection using butt welding; Slurry density close to 1.05 , into the filter (filter $5 \mathrm{~mm}$ round boulders, the thickness should be $50-100 \mathrm{~mm}, 40$ mesh selection), forbidden to force into the hole at the bottom of the collapse hole, concentrated pipe well distribution, continuous drilling, wells should be timely, should not be set aside for too long, or after the completion of the centralized drilling well drilling, and precipitation pipe wells should have a reliable anti-filtration measures to prevent the pumping out of fine sand particles, concrete structure of the design of wells shown in Figure 3. 


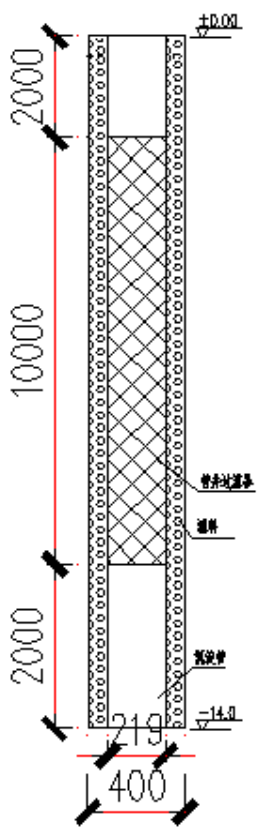

Fig.3 Dewatering well structure drawing

\subsection{Recyclable cable construction}

Construction of anchor cable, according to the following order of construction:

(1) first use of the hole drilling down into the hole, anchor bar $\Phi 15.24$ strand, strand using 1860 level. Anchor cable with non-bonded anchor cable, drilling diameter of 150, the anchor head and pre-tendon connection using extrusion sleeve connection.

(2) The work surface should be subdivided by grading and excavation. The length of each excavation should not be more than $15 \mathrm{~m}$, and the excavation depth should be the same as that of the bottom of the crown (or 300 below the top of the anchor rope). It is strictly forbidden to over excavate. The construction of the next anchor cable can be carried out only after the construction of an anchor cable lock is completed.

(3) grouting using low pressure multiple grouting process, grouting to be slow, steady pressure grouting should last more than 2 minutes to ensure fullness. Grouting volume, grouting pressure and other parameters specifically determined by the test, we must ensure that the anti-pull force to meet the design requirements. Design requirements per meter of cement dosage are not less than $150 \mathrm{~kg}$.

(4) Prestressed anchor cable hole to the design depth should be set up immediately after the strand to prevent holes collapse.

(5) grouting is the key to the success or failure of the anchor, you must strictly control the quality of each anchor grouting and grouting amount; Grouting tube must be sealed with a hose shall not be used as a stop plug cloth.

(6) anchor cable horizontal deviation of not more than 100, the vertical deviation of not more than 50; drill hole horizontal angle of $15^{\circ} / 10^{\circ}$ alternately arranged, the angle error of not more than $3 \%$.

Pre-tensioned and locked: After the strength of anchor grout reaches $80 \%$, pre-tensioning and pre-tensioning are required to design the value of pull-out force of anchor cables, and then lock according to design requirements.

The concrete anchor cable design is shown in Figure 4, figure 5, and the site of the foundation pit supporting construction is shown in Figure 6. 


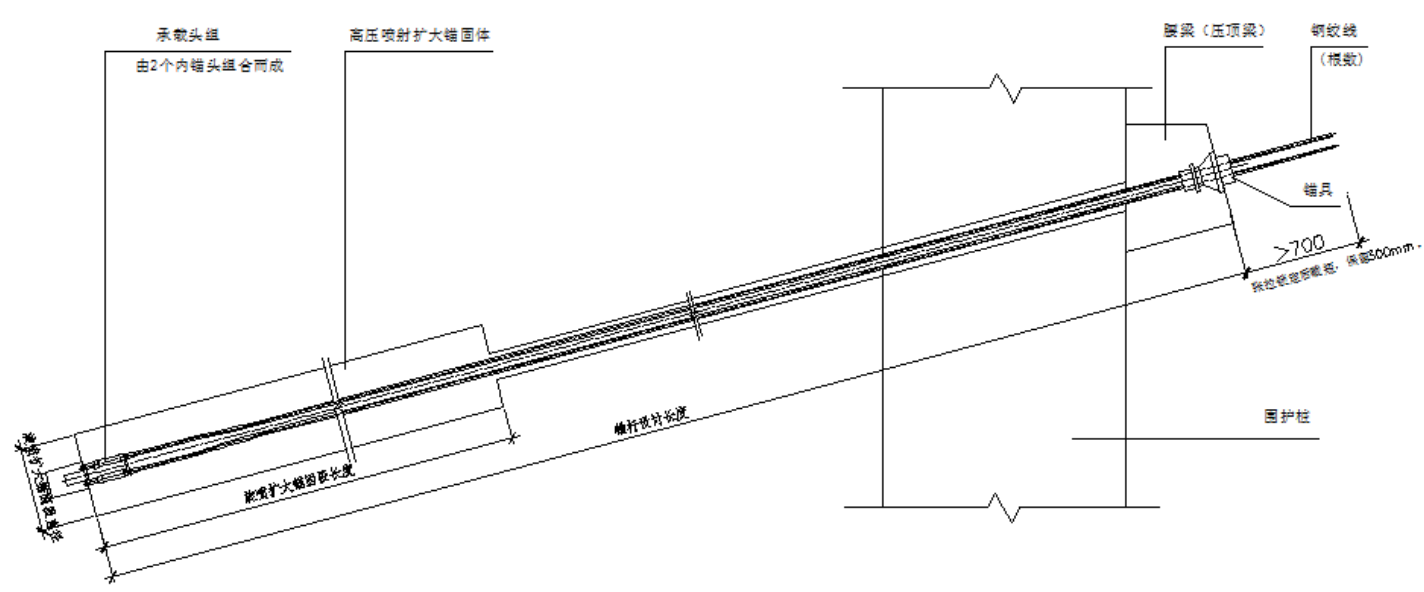

Figure 4 anchor large sample

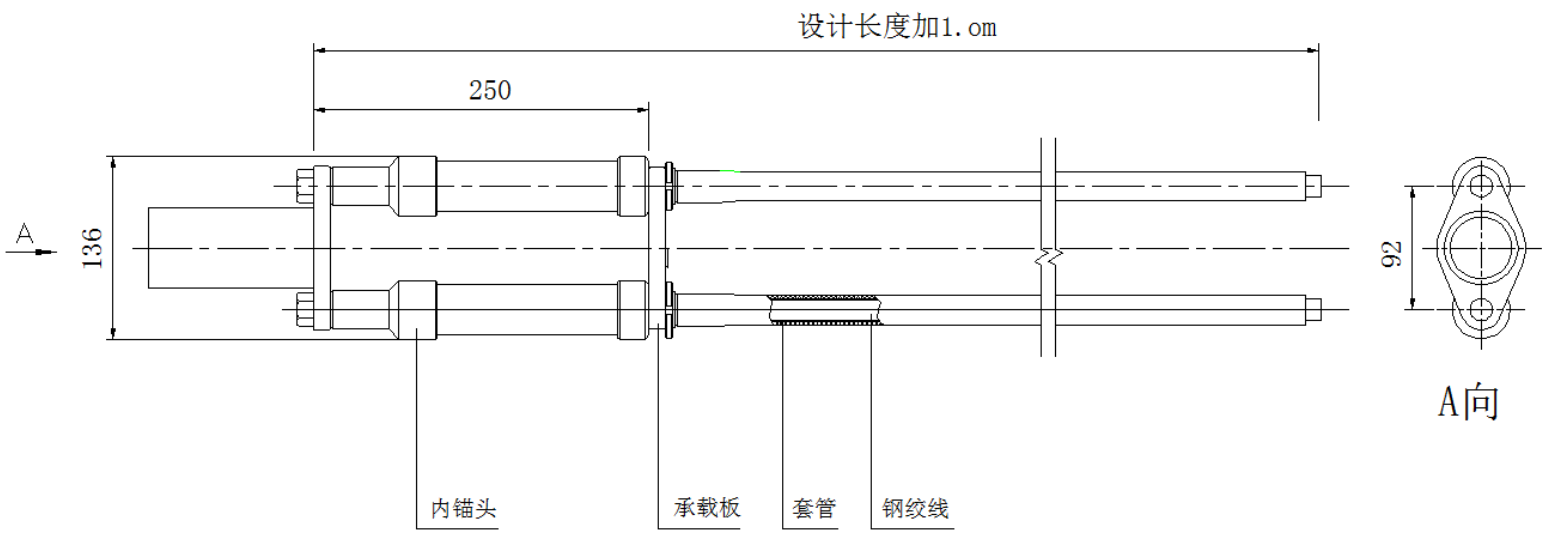

Figure 5 Removable anchor cable structures

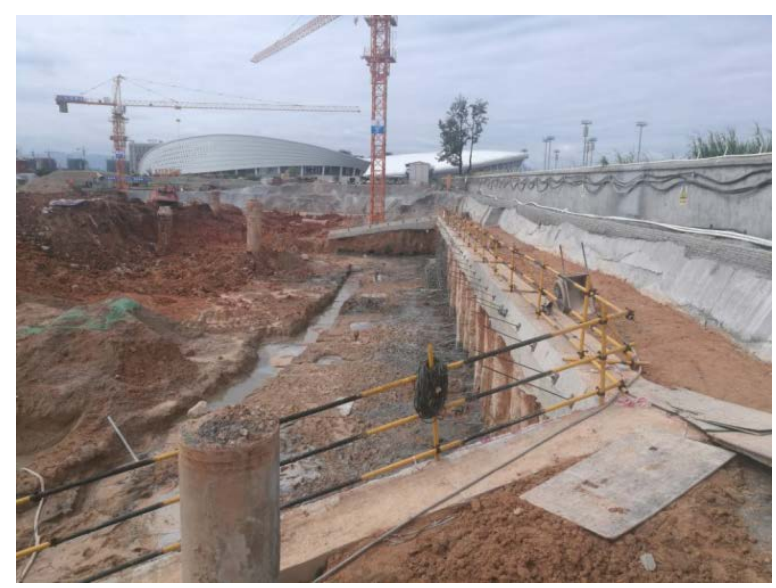

Figure 6 pit support site photos

\subsection{Recyclable cable removal method}

After the main structure of the basement and the shear wall are poured to form an effective continuous horizontal support system, the anchor cables can be demolished and recycled. Demolition of the construction, first of all must be used to remove the jack wire will be pulled out $30-50 \mathrm{~mm}$, remove the anchor plate; and then remove the anchor, jack pressure relief, first with the impact of hammer prestressed tendons to lift the crowd The connection between the pressure sleeve and the ball head core on the prestressing tendon; finally, the prestressing tendon in the anchor rope can be withdrawn by applying appropriate pulling force. 


\section{Pit excavation and anchor recovery during foundation pit monitoring}

The excavation depth of the project is large, and once the problem appears, it is bound to bring tremendous economic losses, personal safety and adverse social impact. In order to effectively protect the safety of the foundation pit and the surrounding structures, timely follow-up of various unfavorable situations that may occur in the process of foundation pit excavation and excavation basement construction, arrange the excavation sequence and construction schedule for construction units and construction units reasonably, And the safety of the surrounding structures, it is necessary to monitor the entire pit excavation process and the cable recovery period. According to the foundation pit excavation pit excavation along the boundary of our questions, a total of 12 horizontal displacement of deep soil monitoring points (CX1 CX12), 8 horizontal displacement of the slope top (A1 A8) and 30 top settlement observation point (A1 A30).

\section{1 deep soil horizontal displacement monitoring}

According to the monitoring data of CX1 CX12, during the observation period, the accumulated maximum displacement value of deep soil horizontal displacement is $23.25 \mathrm{~mm}$ (CX2) and the rate of displacement change is less than 3mm / d, and the accumulated displacement value does not exceed the pre-warning of foundation pit support design Limit (early warning limit: the cumulative displacement value exceeds $40 \mathrm{~mm}$, or its rate of change has been greater than $3 \mathrm{~mm} / \mathrm{d}$ for three consecutive days). During the period from the foundation pit construction to the bottom plate pouring to the recovery of the anchor cable, the displacement rate is in a state of slowing down. No abnormalities are found. The monitoring results are shown in Table 2, and the cumulative displacement curves of each monitoring point are shown in Figure 7.

Table 2 Deep soil horizontal displacement (inclinometer) cumulative displacement statistics

\begin{tabular}{|c|c|c|c|c|c|c|c|c|c|c|c|c|}
\hline Point & CX1 & CX2 & CX3 & CX4 & CX5 & CX6 & CX7 & CX8 & CX9 & $\begin{array}{c}\text { CX1 } \\
\mathbf{0}\end{array}$ & $\mathbf{C X 1 1}$ & $\begin{array}{c}\text { CX1 } \\
\mathbf{2}\end{array}$ \\
\hline $\begin{array}{c}\text { Accumulated } \\
\text { displacement }\end{array}$ & 17.12 & 23.25 & 13.21 & 9.70 & 10.06 & 17.73 & 15.92 & 9.98 & 17.28 & 12.93 & 9.31 & 15.25 \\
\hline
\end{tabular}
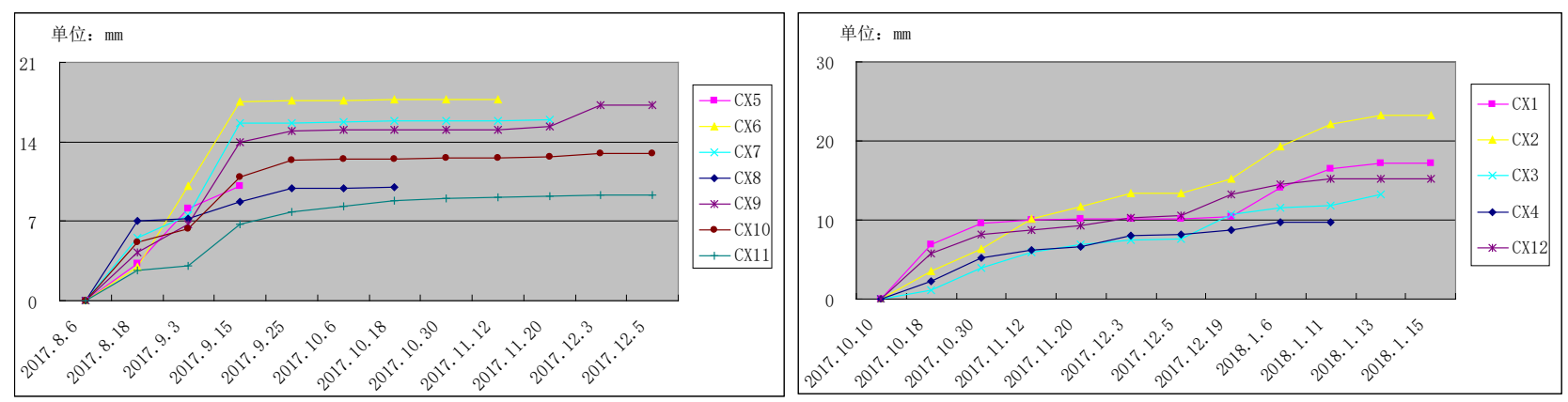

Figure 7 monitoring point cumulative displacements - time curve

\subsection{Pitch horizontal displacement monitoring}

According to the numerical analysis of A1 A8 monitoring, during the observation period, the maximum displacement of the horizontal displacement at the top of the slope is $11 \mathrm{~mm}$ (A7, A8), the rate of displacement change is less than $3 \mathrm{~mm} / \mathrm{d}$, and the accumulated displacement does not exceed the early warning Limits (warning limits: accumulated displacement exceeds $25 \mathrm{~mm}$, or its rate of change has been greater than $3 \mathrm{~mm} / \mathrm{d}$ for three consecutive days). During the period from the foundation pit construction to the bottom plate pouring to the recovery of the anchor cable, the displacement rate is in a state of slowing down with no abnormal conditions. The detailed monitoring data are shown in Table 3. 
Table 3 Top settlement cumulative displacement statistics table

\begin{tabular}{|c|c|c|c|c|c|c|c|c|}
\hline Point & A1 & A2 & A3 & A4 & A5 & A6 & A7 & A8 \\
\hline $\begin{array}{c}\text { Accumulated } \\
\text { displacement }\end{array}$ & 4 & 0 & 6 & 3 & 0 & 5 & 11 & 11 \\
\hline
\end{tabular}

\subsection{Top settlement monitoring}

According to the numerical analysis of A1 A30 monitoring, during the observation period, the cumulative maximum displacement of the top of the slope was $8.32 \mathrm{~mm}$ (A29) and the rate of displacement change was less than $3 \mathrm{~mm} / \mathrm{d}$, and the cumulative displacement did not exceed the pre-warning limits of foundation pit support design (Warning limits: accumulated displacement value exceeds $25 \mathrm{~mm}$, or its rate of change has been greater than $3 \mathrm{~mm} / \mathrm{d}$ for three consecutive days). During the period from the foundation pit construction to the bottom plate pouring to the recovery of the anchor cable, the displacement rate is in a state of slowing down with no abnormalities. The monitoring curve of A29 is shown in Figure 8.

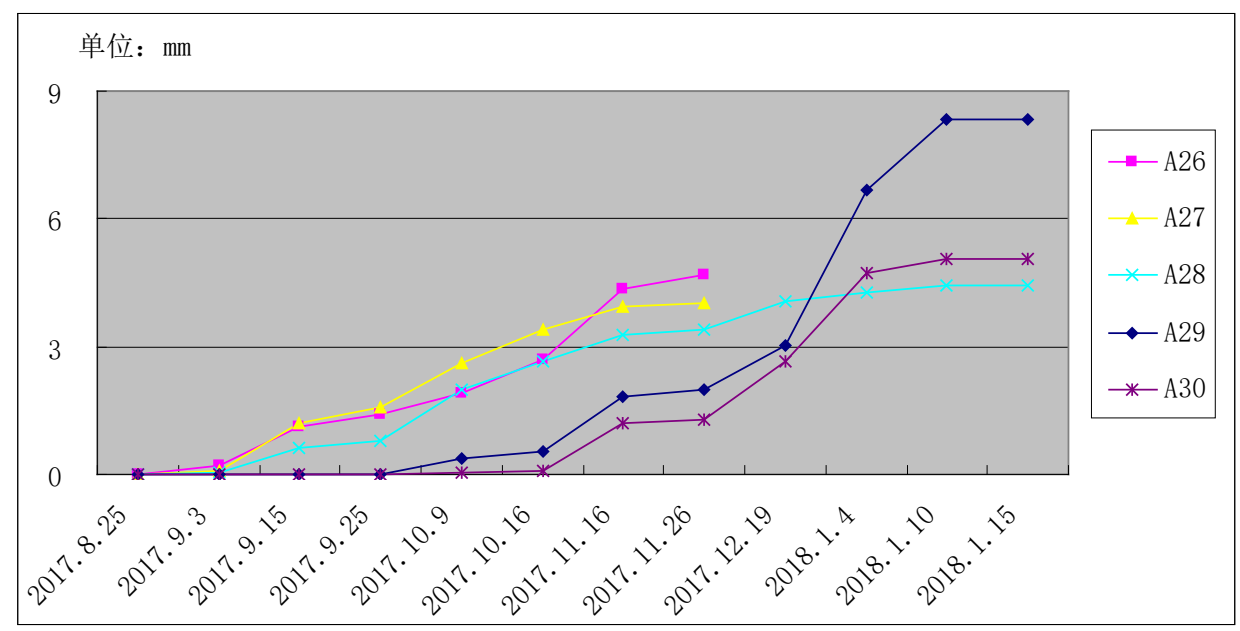

Figure 8 monitoring point cumulative displacements - time curve

\section{Conclusion}

Through the above foundation pit support design, construction and safety monitoring results, we can draw the following conclusions.

(1) The effect of recoverable anchor cable in foundation pit support is stable and safe, and the effect is the same as that of ordinary anchor cable support.

(2) Recyclable cable can not only avoid the environmental pollution caused by the cable left in the soil, but also can recover the anchor cable for secondary use construction to save the construction cost. It is an economical and environmentally friendly foundation pit support form

(3) Recyclable anchor easy to recycle, but still need to be manually recycled, recycling costs more. This will greatly reduce the economic benefits of recyclable cable recovery, which hindered the widespread retractable cable, so in the future still need to continue to study ways to reduce recovery, increase promotion efforts.

\section{References}

[1] Zhang Zheng dry. Recyclable anchor cable technology in large-scale foundation pit support [D]. Guangdong: South China University of Technology, 2013: 2-3. 
[2] Zhao Qijia, Liu Zhenggen.Research and application of recoverable anchor cable in foundation pit supporting engineering [J]. Chinese Journal of Geotechnical Engineering, 2012, 34 (11): 480-483.

[3] Ni Zhengdong.Recyclable anchor in the foundation pit of Fuzhou City, the application [J]. Fujian Construction Science and Technology, 2017 (2): 14-16.

[4] Li Shimin, Xu Bao, Guo Yanpeng.Review and status quo of new types of anchors and cables [J]. Prestressing Technology, 2015,2 (109): 12 -19.

[5] LI Shimin, XU Bao, GUO Yanpeng.Review and status quo of new types of anchors and cables [J] .Proceeding Technology, 2015,2 (109): 12 - 19.

[6] Liu Guobin, Wang Weidong. Foundation Pit Engineering Handbook [M]. 2 editions. Beijing: China Building Industry Press, 2010.

Li Zhaoping, Huang Mingli, Wang Jian et al.Optimized design of reclaiming cable supporting scheme in deep foundation pit of subway [J] .Acta Sciello Sinica, 2012,8 (1): 154-160.

[8] Peng Jianzhong, Zhang Zhenggan, Liu Shaoyue. Application of prestressed recoverable anchor cable in large excavation [J]. Guangdong Water Resources and Hydropower. 2015 (2): 52-55.

About the author: Zheng Suping (1983.02), female, Nanan, Fujian, master's degree, lecturer, mainly engaged in geotechnical teaching and research work, E-mail: 29329151@qq.com. Contact: 13599030675

Fund Project: Middle-aged and Young Teacher Education Research Project in Fujian Province (JAT160549)

Address: Fuzhou Minhou Xiyuan Gong Road on the 2nd Fujian Jiangxia College of Engineering Zip code: 350108 